\title{
PENERAPAN APLIKASI MOBILE LOCATION BASED SERVICE UNTUK PERSEBARAN USAHA MIKRO KECIL MENENGAH DIKABUPATEN JEPARA
}

\author{
Nur Aeni Widiastuti \\ Fakultas Sains dan Teknologi, Program Studi Teknik Informatika \\ Universitas Islam Nahdlatul Ulama Jepara \\ Email: nuraeniwidiastuti@unisnu.ac.id \\ Teguh Tamrin \\ Fakultas Sains dan Teknologi, Program Studi Teknik Informatika \\ Universitas Islam Nahdlatul Ulama Jepara \\ Email: teguh@unisnu.ac.id
}

\begin{abstract}
ABSTRAK
Kabupaten Jepara memiliki sentra industri yang tersebar di wilayahnya. Beberapa sentra industri diantaranya sentra kerajinan gerabah dan genteng, sentra industri tenun troso, sentra industri kerajinan monel, sentra industri mebel, dan lainnya. Persebaran sentra yang ada menyebabkan sentra industri yang lokasinya strategis lebih mudah dikunjungi daripada pengrajin yang lokasinya kurang strategis. Oleh sebab itu, untuk mengatasi permasalahan tersebut dan demi keberlangsungan sentra yang ada maka peneliti mengusulkan untuk perancangan aplikasi mobile persebaran Usaha Mikro Kecil Menengah dengan pengembangan metode location based service. Aplikasi mobile ini terintegrasi dengan google Maps API sehingga pembeli dapat mengakses jarak lokasi sentra yang dicari dengan lokasi dia berada saat itu. Metode ini memiliki kelebihan diantaranya: (1)informasi lokasi yang diberikan real time, (2)sebagai penunjuk arah untuk lokasi yang dituju. Hasil penelitian ini dapat dilihat dari pengujian blackbox testing dan uji kelayakan aplikasi kepada pengguna menghasilkan persentase sebesar $77 \%$ yang dinyatakan sangat layak untuk digunakan.
\end{abstract}

Kata kunci: location based service; mobile application; GRAPPLE.

\section{ABSTRACT}

Jepara Regency has industrial centers spread across its territory. Some industrial centers include pottery and tile craft centers, troso weaving industry centers, copper craft industry centers, furniture industry centers, and others. The distribution of existing centers makes strategic industrial centers easier to visit than craftsmen whose locations are less strategic. Therefore, to overcome these problems and for the sake of the sustainability of the existing centers, the researchers propose to design a mobile application for the distribution of Micro Small and Medium Enterprises by developing location-based service methods. This mobile application is integrated with the Google Maps API so that buyer can access the distance of the location of the center sought by the location he was at that time. This method has advantages including: (1) location information provided in real-time, (2) as a direction for the destination location. The results of this study can be seen from the black box testing and the appropriateness of the application to the user resulting in a percentage of $77 \%$ which is declared eligible for use.

Keywords: location based service; mobile application; GRAPPLE.

\section{PENDAHULUAN}

Perkembangan usaha mikro kecil dan menengah (UMKM) sangat mempengaruhi perekonomian di suatu daerah terutama di kabupaten Jepara. Penyelenggaraan dan penggolongan UMKM diatur dalam perundang-undangan No 20 tahun 2008 kerjasama antara pemerintah dan UMKM perlu dilakukan secara menyeluruh, optimal, dan berkesinambungan melalui pengembangan iklim yang kondusif, pemberian kesempatan berusaha, dukungan, perlindungan, dan pengembangan usaha seluas-luasnya, untuk mewujudkan pertumbuhan ekonomi,pemerataan dan peningkatan pendapatan rakyat, penciptaan lapangan kerja, dan pengentasan kemiskinan[1].

Kabupaten Jepara menurut Badan Pusat Statistik tahun 2015 memiliki jumlah industri 18. 695 unit yang tersebar diantaranya unit usaha kerajinan rotan, tenun troso, monel, gerabah, genteng, furniture kayu, rokok, kerajinan kayu, makanan, konveksi, bordir, mainan anak, industri rumahan, kerajinan simping dan kerajinan kuningan [2]. 
Seiring berkembangnya UMKM di Jepara membuat para pembeli mempunyai banyak pilihan dengan kualitas beragam dan harga yang bersaing. Banyaknya jenis sentra industri yang ada dapat dijadikan sebagai objek pariwisata yang potensial jika dikembangkan dan dikelola dengan baik. Permasalahan yang muncul di lapangan adalah : 1) Banyaknya sentra industri yang belum didukung dengan media promosi untuk meningkatkan potensi pasar, dan 2) Lokasi yang kurang strategis membuat pengrajin kalah bersaing. Sehingga menyulitkan para pembeli untuk mencari lokasi sentra industri yang bagus dan sesuai dengan yang dicari.

Seiring perkembangan teknologi dan pesatnya aplikasi mobile berbasis android. Maka metode location based service diusulkan untuk menyelesaikan masalah tersebut. Dengan metode penentuan tempat yang memberikan informasi yang relevan sesuai dengan pendaftaran titik koordinat lokasi sentra industri yang terintegrasi dengan google map memudahkan user dalam pencarian lokasi terdekat [3]. Selain itu dengan memakai platform android, informasi akan lebih mudah untuk diakses melalui handphone. Jadi, jika seseorang yang sedang mengadakan perjalanan ke tempat yang belum dikenalnya sama sekali tidak perlu khawatir akan tersesat. Dengan teknologi ini kita bisa mencari dan menuju suatu tempat cukup dengan mengikuti peta jalan yang bisa diakses setiap saat dari gadget maupun smartphone yang kita punya [4].

Beberapa penelitian terkait yang pernah dilakukan oleh azizah dan widiastuti (2018) tentang pemetaan UMKM dengan algoritma K-Means cluster berbasis teknologi geolocation yang diimplementasikan dalam aplikasi android dengan metode waterfall. Pada penelitian ini data UMKM di cluster dengan algoritma K-Means kemudian hasil dari cluster dimasukkan ke dalam aplikasi android yang ditampilkan perkategori sentra industri yang ada. Aplikasi yang dihasilkan kemudian dilakukan pengujian blackbox dengan skala likert dihasilkan skor $96.4 \%$ [2].

Penelitian tentang sistem informasi geografis pencarian agen travel dan bus dengan menggunakan metode djikstra dihasilkan bahwa aplikasi mobile yang berisi modul map, agen, riwayat, dan tentang aplikasi sangat membantu dalam pencarian agen travel dan bus yang terdekat dengan user yang berada di kota Semarang [5].

Penelitian tentang pengembangan aplikasi mobile location based service berbasis android untuk pencarian lokasi rumah sakit berdasarkan asurasi kesehatan di kota Malang menggunakan metode agile. Pada penelitian ini yang diukur adalah pengujian aplikasi mulai dari uji validitas hasil blackbox (validity tes) dan uji kegunaan (usability tes) ke user terhadap penggunaan aplikasi yang dihitung dengan menggunakan skala likert dan dihasilkan uji validitas $100 \%$ dan uji kegunaan $92.91 \%$. Berdasarkan hasil penelitian dapat disimpulkan bahwa pengguna/user dapat menggunakan aplikasi tersebut dangan mudah dan sangat membantu [6]

Berdasarkan beberapa penelitian terkait maka permasalahan yang ada akan diselesaikan dengan Perancangan aplikasi mobile persebaran UMKM di Jepara berbasis lokasi yang berisi informasi tentang lokasi sentra industri berbasis map yang bisa mengukur posisi saat ini dengan jarak sentra industri yang akan dikunjungi dan deskripsi dari sentra industri tersebut. Tujuan dari penelitian ini adalah memudahkan pembeli dalam mencari sentra industri yang dituju dan Meningkatkan media promosi pada sentra industri tersebut agar lebih dikenal. Oleh sebab itu, metode location based service diusulkan karena memiliki kelebihan: 1) dapat memberikan informasi tambahan mengenai posisi benda bergerak, 2) Jarak lokasi yang ingin dituju, 3) petunjuk arah untuk ke lokasi.

\section{METODOLOGI PENELITIAN}

Metodologi Penelitian dalam penelitian ini akan menjelaskan mulai dari tahapan pengumpulan data sampai penarikan kesimpulan secara eksplisit. Lokasi penelitian ini berada di sentra industri kabupaten Jepara dengan menentukan titik koordinat lokasi industri dengan mengambil sampel \pm 20 toko per sentra industri. Pada penelitian ini terdapat 7 sentra industri antara lain : gerabah dan genteng yang berada di Kecamatan Mayong, monel di desa Kriyan, kain tenun troso berada di desa Troso, mebel di kecamatan Tahunan, seni ukir dan patung di desa Mulyoharjo, rotan di daerah desa Teluk Wetan dan home industry di daerah Mantingan dan Bangsri.

Pengumpulan data dilakukan dengan metode studi pustaka, observasi, wawancara dan dokumentasi. Tahapan dalam penelitian ini menggunakan tahapan GRAPPLE (Gudline for Rapid APPlication Engineering) yang meliputi : Requirement Gathering, Analysis, Design, Development, dan Deployment. Metode ini merupakan penyederhanaan dari metode Rapid Application Development (RAD) yang penyelesainnya terdiri atas beberapa tindakan dan setiap tindakannya menghasilkan produk berupa diagram UML[7]. 


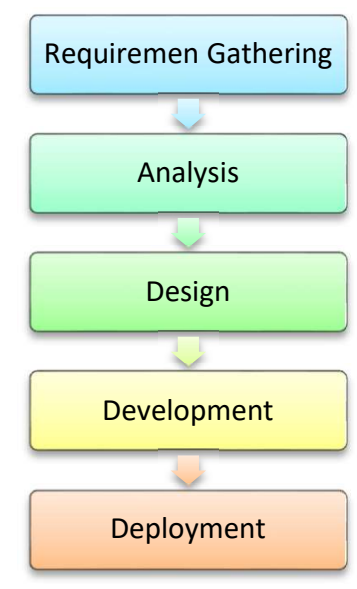

\section{Gambar 1. Tahapan Metode GRAPPLE [7]}

Berdasarkan Gambar 1, berikut uraian tahapan penelitian.

1) Requiremen Gathering

Pada tahapan ini adalah pengumpulan data. Teknik yang digunakan adalah studi pustaka melalui jurnal dan buku terkait dan teknik wawancara dan dokumentasi ke 7 sentra industri yang sudah ditentukan untuk menentukan titik koordinat pada pemetaannya di google map.

2) Analysis

Pada tahapan ini meliputi :

a) Analisis kebutuhan alat dan bahan

b) Dalam proses membangun aplikasi peralatan yang digunakan yaitu berupa perangkat keras dan perangkat lunak serta menggunakan data berupa informasi lengkap tentang masing-masing sentra industri beserta koordinat lokasi sebagai bahan dari penelitian

c) Analisis kebutuhan data dan informasi, yaitu menganalisis data yang diperlukan dan informasi yang akan dihasilkan dari pengolahan data.

d) Analisis kebutuhan sistem, yaitu kebutuhan yang berkaitan dengan fitur yang dibutuhkan oleh industri yang harus ada pada aplikasi untuk digunakan oleh pengguna.

Adapun kegiatan yang dilakukan pada tahap ini adalah :

a) Mengidentifikasi masalah yang ada pada proses observasi

b) Mengidentifikasi kebutuhan teknologi informasi untuk UMKM sesuai dengan sentra industrinya.

3) Design

Tahap design digunakan untuk membuat penyelesaian masalah yang diusulkan dari tahapan sebelumnya sampai diperoleh rancangan yang tepat. Termasuk dalam tahapan ini adalah implementasi model dan diagram serta perancangan interface. Selanjutnya proses membuat kode pemograman akan masuk pada tahap development.

4) Development

Tahap ini ditangani oleh pengembang program untuk membangun koding pemograman dan user interface. Untuk pembuatan aplikasi ini peneliti menggunakan Android Studio dan kotlin 1.3.30 untuk bahasa pemrogramannya, firebase untuk penyimpanan database, Android SDK Build Tools 28 untuk Alat kompilasi dari kode program ke paket aplikasi Android yang bisa dijalankan di smartphone.

5) Deployment

Tahap deployment adalah tahapan dimana pendistribusian produk yang dihasilkan kepada pengguna. Aplikasi yang sudah jadi akan di upload di playstore dan diuji angket ke pengguna.

Pengujian yang dilakukan adalah blackbox testing, dan uji kelayakan aplikasi ke pengguna yang akan diolah dengan rumus skala likert. 
$P=\frac{f}{n} \times 100 \%$

Keterangan:

$\mathrm{P}=$ Presentase $(\%)$

$f=$ Frekuensi jumlah hasil dari setiap jawaban validasi

$n=$ Jumlah nilai skor ideal dari seluruh butir pertayaan

Tabel 1. Klasifikasi persentase kelayakan aplikasi

\begin{tabular}{ccc}
\hline No & Presentase & Kriteria \\
\hline 1 & $75 \%-100 \%$ & Sangat Layak \\
2 & $50 \%-75 \%$ & Layak \\
3 & $25 \%-50 \%$ & Cukup Layak \\
4 & $1 \%-25 \%$ & Kurang Layak \\
\hline
\end{tabular}

Penyebaran angket untuk uji kelayakan aplikasi terhadap pengguna akan dilakukan ke 100 orang pengguna. Dengan mengunduh aplikasi yang sudah didaftarkan di playstore dan mengisi angket yang telah disediakan akan diketahui aplikasi yang dibuat layak untuk dipublikasikan atau tidak. Ketika aplikasi layak untuk dipublikasikan. Maka wisatawan bisa mengunduh aplikasi tersebut untuk mempermudah dalam pencarian sentra industri yang ada di kabupaten Jepara.

\section{HASIL DAN PEMBAHASAN}

Pada penelitian ini menggunakan tahapan perancangan GRAPPLE yang dimulai dari tahapan :

1) Requirement Gathering

Pada tahapan ini adalah pengumpulan data. Teknik yang digunakan adalah studi pustaka melalui jurnal dan buku terkait, dan teknik wawancara dan dokumentasi ke Observasi ke Dinas Koperasi, UKM, Tenaga Kerja dan Transmigrasi Kabupaten Jepara serta ke beberapa sentra industri yang ada untuk menentukan titik poin pada pemetaannya di google map serta deskripsi tentang sentra industri yang ada di Jepara. Sentra Industri yang akan dituju adalah home industry, mebel, tenun ikat troso, rotan, kerajinan seni patung, gerabah dan genteng, kerajinan monel.

Tabel 2. Hasil observasi ke sentra Industri

\begin{tabular}{clr}
\hline No & Sentra Industri & Jumlah \\
\hline 1 & Gerabah dan Genteng & 14 \\
2 & Monel & 13 \\
3 & Rotan & 11 \\
4 & Kain Tenun Troso & 20 \\
5 & Mebel & 30 \\
6 & Seni Patung dan Ukir & 7 \\
7 & Home Industry & 15 \\
\hline
\end{tabular}

2) Analisis Kebutuhan Alat dan Bahan

Dalam proses membangun aplikasi peralatan yang digunakan yaitu berupa perangkat keras dan perangkat lunak serta menggunakan data berupa informasi lengkap tentang masing-masing sentra industri beserta koordinat lokasi sebagai bahan dari penelitian

3) Design

Use case diagram mendefinisikan fitur yang terdapat pada aplikasi yang menunjukkan interaksi antara pengguna dan sistem dalam menggunakan fitur yang ada. Berikut merupakan use case diagram dari aplikasi APLIKASI PERSEBARAN UMKM 


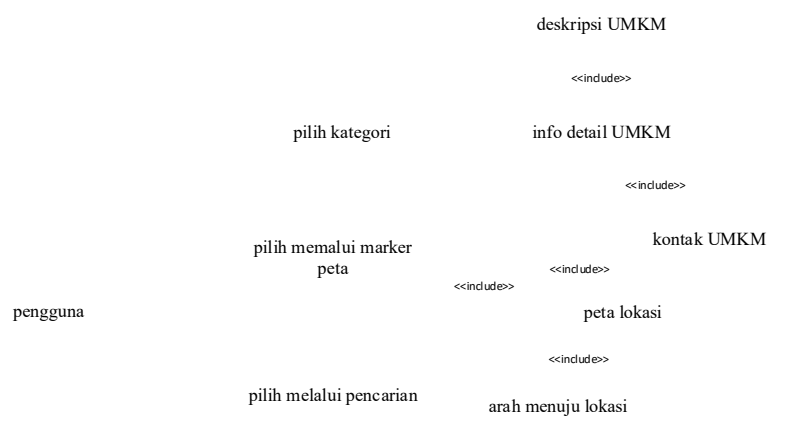

\section{Gambar 2. Use case Diagram Aplikasi}

Berikut merupakan deskripsi Gambar 4 use case diagram Aplikasi Persebaran UMKM .

Tabel 1. Tabel deskripsi use case diagram

\begin{tabular}{|c|c|c|}
\hline \multicolumn{3}{|r|}{ Aktor: Pengguna } \\
\hline No. & Use Case & Deskripsi \\
\hline 1 & Pilih kategori & Pengguna melihat daftar UMKM berdasarkan kategori. \\
\hline 2 & Pilih melalui marker & $\begin{array}{l}\text { Pengguna disajikan tampilan peta kabupaten Jepara dengan marker yang } \\
\text { merupakan titik lokasi dari semua UMKM yang terdaftar pada sistem. }\end{array}$ \\
\hline 3 & $\begin{array}{l}\text { Pilih melalui } \\
\text { pencarian }\end{array}$ & zuna dapat melakukan pencarian menggunakan nama UMKM. \\
\hline 4 & Info detail UMKM & $\begin{array}{l}\text { Pengguna mendapkan informasi tentang UMKM yang meliputi, nama, } \\
\text { alamat, koordinat, nomor telepon, foto, dan deskripsi. }\end{array}$ \\
\hline 5 & Deskripsi UMKM & Pengguna mengakses deskripsi melalui info detail UMKM \\
\hline 6 & Kontak UMKM & $\begin{array}{l}\text { Pengguna melakukan kontak melalui telepon atau pesan singkat } \\
\text { menggunakan nomor telepon yang terdaftar di info detail UMKM. }\end{array}$ \\
\hline 7 & Peta lokasi & $\begin{array}{l}\text { Pengguna dapat melihat semua lokasi UMKM di peta menggunakan } \\
\text { marker. }\end{array}$ \\
\hline 8 & Arah menuju lokasi & $\begin{array}{l}\text { Pengguna diarahkan menuju lokasi berdasarkan koordinat pengguna dan } \\
\text { koordinat UMKM menggunakan aplikasi Google Maps atau membuka } \\
\text { Google Maps melalui browser. }\end{array}$ \\
\hline
\end{tabular}

Perancangan tampilan antarmuka yang dilakukan merupakan tahapan sebelum melakukan implementasi atau coding agar dapat mencapai hasil yang maksimal. Rancangan tampilan antarmuka meliputi rancangan halaman splashscreen, halaman utama, halaman kategori UMKM, halaman peta UMKM, halaman pencarian, halaman daftar UMKM, halaman detail UMKM, dan halaman tentang aplikasi.

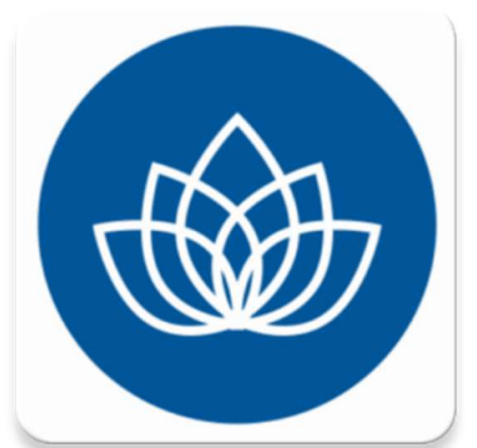

\section{Gambar 3. Tampilan Splash Screen Aplikasi Persebaran UMKM Jepara}

Tampilah splash screen menampilkan logo aplikasi. Jika aplikasi pertama kali dijalankan splash screen berfungsi sebagai meminta perijinan aplikasi untuk akses GPS dan telepon dari smartphone. 

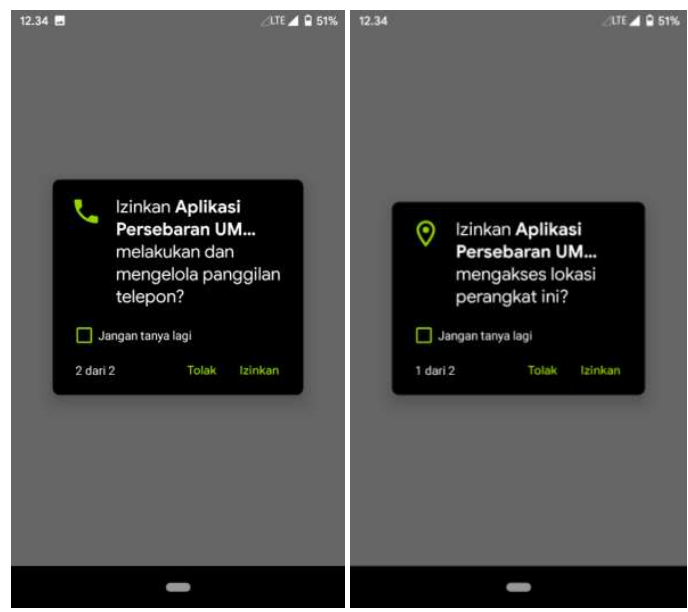

\section{Gambar 4. Tampilan Permintaan Ijin Akses Gps Dan Akses Telepon}

Pada Gambar 4 aplikasi akan menkonfirmasi kepada pengguna untuk hak akses GPS dan telepon pada handpone android pengguna. Pengguna mempunyai dua jawaban yaitu untuk menolak dan mengizinkan aplikasi tersebut untuk bisa diinstal di handponenya.

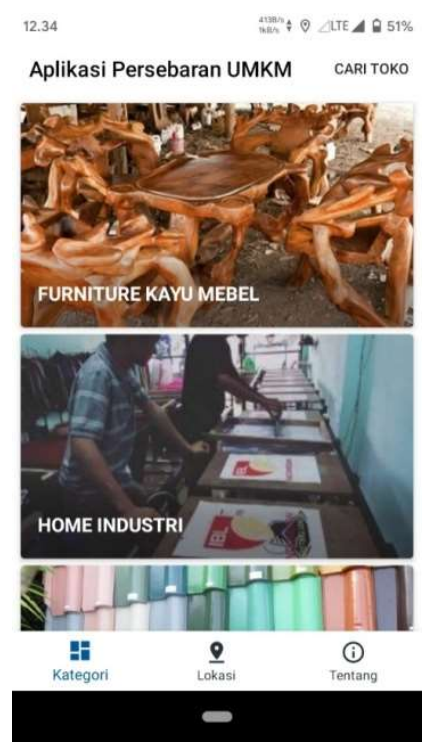

Gambar 5. Tampilan Utama

Halaman utama berisikan tiga tab yaitu tab kategori, tab lokasi, dan tab tentang aplikasi. Halaman kategori terletak di halaman utama aplikasi. Halaman ini untuk memudahkan pengguna menemukan berdasarkan kategori yang terdaftar di aplikasi.

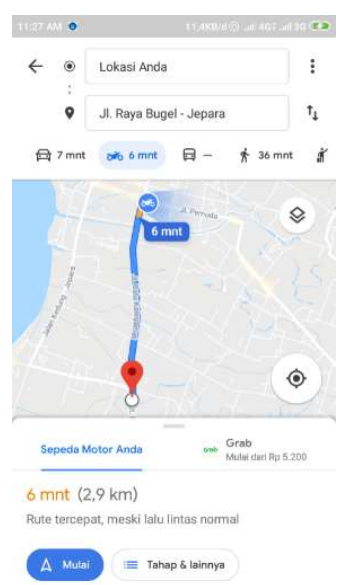

Gambar 6. Halaman Peta Lokasi 
Halaman ini terletak di halaman utama aplikasi namanya menu Lokasi. Pada Halaman ini pengguna bisa mengakses lokasi sentra industri yang dituju dengan mengetikkan dikolom pencarian atau bisa memilih sentra industri yang dipilih pada menu kategori. Halaman ini memudahkan pengguna menemukan lokasi UMKM yang terdaftar pada aplikasi dengan jarak terdekat dari lokasi pengguna.

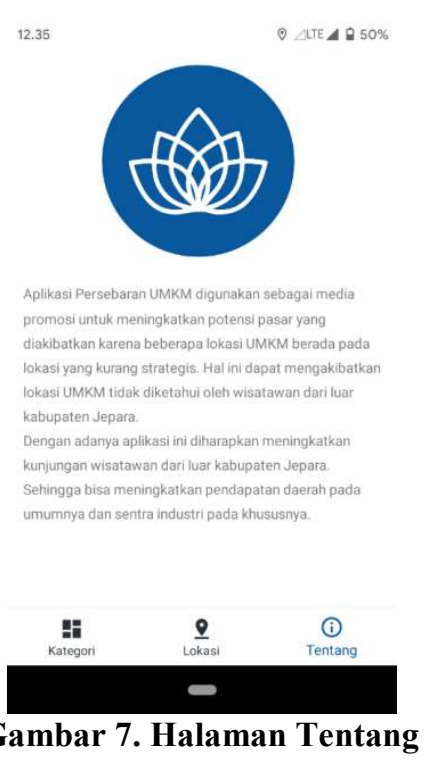

Halaman ini terletak di halaman utama aplikasi. Halaman ini Tentang menjelaskan deskripsi dari aplikasi Persebaran UMKM Jepara.

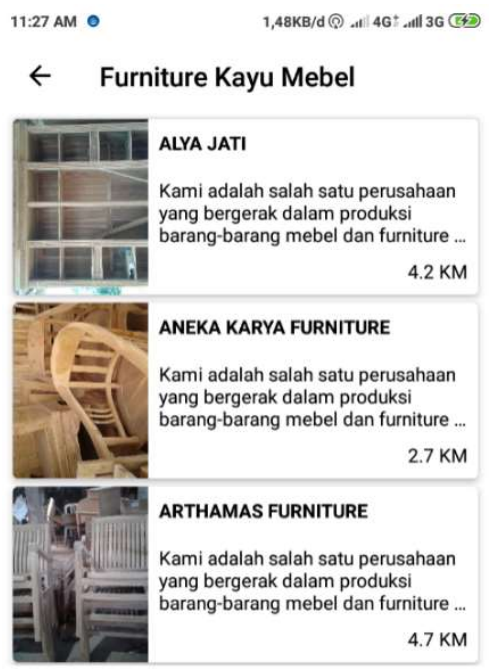

Gambar 8. Tampilan daftar UMKM

Halaman daftar UMKM merupakan tampilan daftar UMKM berdasarkan kategori yang terdaftar di aplikasi. Setiap item dalam daftar memiliki informasi foto, nama UMKM, deskripsi, dan perkiraan jarak lokasi UMKM dengan pengguna.

Setelah aplikasi jadi tahapan berikutnya adalah pengujian aplikasi. Metode pengujian yang digunakan untuk aplikasi UMKM KITA adalah black box testing. Pengujian dilakukan terhadap seluruh tampilan aplikasi sesuai fungsi aplikasi dan uji kelayakan sistem terhadap pengguna. Dari hasil pengujian dihasilkan Tabel 2.

Tabel 4. Hasil Pengujian Sistem

\begin{tabular}{|c|c|c|c|}
\hline No & $\begin{array}{c}\text { Jenis } \\
\text { Pengujian }\end{array}$ & $\begin{array}{c}\text { Hasil } \\
\text { Pengujian }\end{array}$ & Kriteria \\
\hline 1 & $\begin{array}{l}\text { Black Box } \\
\text { Testing }\end{array}$ & $97 \%$ & $\begin{array}{l}\text { Sangat } \\
\text { Layak }\end{array}$ \\
\hline 2 & $\begin{array}{l}\text { Uji Kelayakan } \\
\text { Pengguna }\end{array}$ & $77 \%$ & $\begin{array}{l}\text { Sangat } \\
\text { Layak }\end{array}$ \\
\hline
\end{tabular}


Hasil pengujian sistem dihasilkan pengujian blackbox $97 \%$ dengan kriteria sangat layak dan uji kelayakan kepada pengguna $77 \%$ dengan kriteria sangat layak. Berdasarkan hasil pengujian dapat disimpulkan bahwa aplikasi bisa digunakan oleh pengguna dan valid untuk digunakan.

Penelitian ini merupakan penelitian lanjutan dari Azizah dan Widiastuti (2018) tentang pemetaan UMKM dengan menampilkan aplikasi yang berbasis geolocation. Kelemahan dari penelitiannya adalah (1) pada aplikasi tidak ada filter jarak dalam pemilihan jarak yang terdekat dan terjauh, (2) tidak adanya fiture favorite sebagai pemilihan terbaik dalam pelayanan UMKM , (3) Database yang masih sedikit. Oleh sebab itu, penelitian ini mengembangkan tentang (1) Adanya filter jarak untuk pemilihan lokasi yang terdekat dan terjauh, (2) Penambahan sentra industri, (3) Keakuratan GPS.

\section{KESIMPULAN}

Permasalahan pada penelitian ini adalah lokasi sentra industri yang kurang strategis sehingga pembeli yang datang sedikit. Oleh sebab itu, untuk keberlangsungan sentra industri yang ada. Maka peneliti mengusulkan aplikasi mobile location based service untuk persebaran UMKM di Kabupaten Jepara. Penggunaan location based service ini diusulkan karena memiliki kelebihan diantaranya: (1)informasi lokasi yang diberikan real time, (2)sebagai penunjuk arah untuk lokasi yang dituju.

Pada penelitian ini menggunakan metode GRAPPLE yang merupakan penyederhanaan dari metode RAD dengan pengujian sistem menggunakan black box dan uji kelayakan pengguna. Dari hasil pengujian dihasilkan pengujian black box adalah $97 \%$ dengan kriteria sangat layak dan uji kelayakan kepada pengguna $77 \%$ dengan kriteria sangat layak. Dari hasil tersebut berarti aplikasi yang dibuat dinyatakan valid dan layak untuk digunakan. Aplikasi ini bisa di download di playstore https://play.google.com/store/apps/details?id=c.aplikasipersebaranumkm.

Saran untuk penelitian selanjutnya adalah perancangan marketplace untuk UMKM yang ada di Jepara dan bisa disosialisasikan ke masyarakat untuk menggunakannya.

\section{UCAPAN TERIMA KASIH}

Peneliti mengucapkan terima kasih kepada DRPM DIKTI yang telah mendanai penelitian ini hingga selesainya dalam kategori Penelitian Kompetitif Nasional dengan skema Penelitian Dosen Pemula (PDP) dengan nomor kontrak LLDIKTI 6 dengan LPPM : 032/L6/AK/SP2H/PENELITIAN/2019

\section{DAFTAR PUSTAKA}

[1] RepublikIndonesia, “Government Regulation No. 20/2008," UU No. 20 Tahun 2008, no. 1, pp. 1-31, 2008.

[2] N. A. Widiastuti and N. A. Azizah Widiastuti, "Teknologi Geolocation Berbasis Android dengan Metode K-Means untuk Pemetaan UMKM di Kabupaten Jepara," J. Sist. Inf. Bisnis, vol. 8, no. 2, p. 218, 2018.

[3] A. R. Bahrehdar, O. Koblet, and R. S. Purves, "Approaching location-based services from a placebased perspective: from data to services?," J. Locat. Based Serv., vol. 13, no. 2, pp. 73-93, 2019.

[4] U. Ependi and S. Suyanto, "Implementasi Location Based Service Pada Aplikasi Mobile Pencarian Halte BRT Transmusi Palembang," J. Inf. Syst. Eng. Bus. Intell., vol. 2, no. 1, p. 33, 2016.

[5] M. R. Kurniawan, O. D. Nurhayati, and K. T. Martono, "Sistem Informasi Geografis Pencarian Lokasi Agen Bus dan Travel Terdekat di Kota Semarang Berbasis Mobile dengan Metode Dijkstra," J. Teknol. dan Sist. Komput., vol. 3, no. 2, p. 302, 2017.

[6] S. P. Seputro, H. Tolle, and K. C. Brata, "Pengembangan Aplikasi Mobile Location Based Service Berbasis Android Untuk Pencarian Lokasi Rumah Sakit Di Kota Malang Berdasarkan Asuransi Kesehatan Dengan Metode Agile System Development," J. Pengemb. Teknol. Inf. dan Ilmu Komput. Univ. Brawijaya, vol. 3, no. 1, pp. 781-791, 2019.

[7] A. Yuliawan, N. Sakti, Y. Priyandari, and M. Hisjam, "Perancangan Sistem Informasi Manajemen Auditor Teknologi pada Sistem Nasional Audit Teknologi ( SNAT ) Menggunakan Metode Grapple," Semin. Int. dan Konf. Nas. IDEC 2016, no. February 2017, pp. 364-373, 2016. 